\title{
Impact of Smokeless Tobacco use among the women's health in the selected old town of Bangladesh
}

\author{
AE Noor $^{1 *}$, N Amin ${ }^{2}$, MTH Chowdhury ${ }^{3}$, TM Shanta ${ }^{4}$ \\ ${ }^{1}$ Dept. of Dental Public Health, Sapporo Dental College and Hospital, Dhaka, Bangladesh. \\ ${ }^{2}$ Dept. of Oral and Maxillofacial Surgery, Sapporo Dental College and Hospital, Dhaka, \\ Bangladesh. \\ ${ }^{3}$ Dept. of Dental Public Health, Sapporo Dental College \& Hospital, Dhaka, Bangladesh. \\ ${ }^{4}$ Sapporo Dental College and Hospital, Dhaka, Bangladesh. \\ *Corresponding E-mail: rajet.elahi@gmail.com
}

\begin{abstract}
Purpose: The purpose of this cross-sectional study was to find out the impact of Smokeless Tobacco (SLT) use among the women's health in the selected old town of Bangladesh. Methods: About 105 women using Smokeless Tobacco (SLT) were collected by a structured pretested face to face questionnaire under purposive sampling technique during April to June 2012.Data were presented in graphical and tabular pattern whereas analysis was done by SPSS (statistical package for the social sciences) version-17. Results: Among the 105 respondents, majority $63 \%$ were housewives and only $1.9 \%$ was service holder. The duration of using smokeless tobacco (SLT) with betel leaf was $48.4 \%$ who were using Sadapata for more than 10 years. In addition, 36.6\%, 52.6\%, 38.8\% smokeless tobacco (SLT) uses Zarda, gul and khaini for 5 years. The reason behind using smokeless tobacco (SLT) was stated as fun by $40 \%$ respondents. Almost $68.6 \%$ respondents think smokeless tobacco (SLT) do not cause any harm in the oral cavity while only $31.4 \%$ stated smokeless tobacco (SLT) cause harm in the oral cavity. There was significant association between occupation and regular use of smokeless tobacco (SLT) ( $p<0.05)$. Finally, among the smokeless tobacco (SLT)-Zarda was mostly used by the women which is harmful for general health and oral health. Conclusion: Finally considering the harmful impact with its consequences smokeless tobacco (SLT) use which was unfortunately unknown and unaware by the general population mostly women. It was reflected in my research about $63 \%$ user were housewives. So, it is necessary to implement a very strong comprehensive monitoring and evaluation system both national and international region to stop the use of smokeless tobacco by involving government, nongovernment policy makers immediately. Now it is the time to realize in a true sense by our local political personnel and government to make emergency step and making network system so that we can make slogan Banning of Smokeless Tobacco (SLT) at national and international level around the world.
\end{abstract}

Keywords: Smokeless Tobacco (SLT), Zarda, Gul, Sadapata, Khaini, Betel leaf

Received: 19 April, 2021

Accepted: 05 May, 2021

Published: 17 May, 2021

\section{Introduction}

Postpartum According to the status of Bangladesh, which is one of the poorest countries of the world with various health hazards. Both young and older populations are the most vulnerable group in the world. To improve country health status their participation is required. Smokeless tobacco consumption considered the greatest single health hazard for mankind. High incidence of oral cancer in poor country could be an effect of this cultural habit of 
chewing smokeless tobacco such as loose-leaf, pouch, or snuff, gull, jardah, but unfortunately, the majority of Bangladeshi people are unaware of the health risks of these social habits. Smokeless tobacco is strongly associated with periodontal tissue destruction and is considered a risk factor for: Periodontitis, Tooth loss, Hypertension, Elevated serum cholesterol, Coronary heart diseases, Stroke, Lung cancer, Gangrene. All of these factors increase the cost of the family environment leading to hamper in community as well as national level [1].

The prevalence of use of smokeless tobacco varies widely across countries and regions, with particularly high rates of consumption in some areas of South-East Asia. For example, in Bangladesh and India, levels of use of smokeless tobacco surpass cigarette smoking [2]. In Sweden, use of smokeless tobacco is also common, and in 2010 was about 10 times higher than the rest of Europe [3].In contrast, use of these products in Australia is very low; results from the 2013 National Drug Strategy Household Survey showed that only $0.3-0.4 \%$ of Australians aged 14 years or older reported using chewing tobacco, snus, or snuff in the past 12 months [4]. However, prevalence of use among some minority groups is much higher. A 2014 survey of South Asian residents in Sydney found rates of having ever used smokeless tobacco products, using it more than 100 times, and current use at $72.1 \%, 65.9 \%$, and $17.1 \%$, respectively [5]. Chewing tobacco is also used in some Indigenous communities, particularly in Central Australia. Aboriginal Australians may chew commercially available tobaccos mixed with ash from certain trees, or native tobaccos (pituri) [6]. The health effects of using smokeless tobacco, and the wider public health impact, are a source of debate among the tobacco control community and healthcare professionals. Many smokeless tobacco products contain high concentrations of nicotine and deliver comparable daily systemic doses to those obtained from cigarette smoking; therefore, use of smokeless tobacco can be as addictive as smoking cigarettes.

Smokeless tobacco also contains several known carcinogens, with levels varying based on product characteristics including tobacco type, additives, alkalinity, and processing methods. Exclusive smokeless tobacco users can be exposed to even higher levels of nicotine and toxicants than exclusive cigarette smokers. Plant materials such as areca nut or tonka bean, along with other additives, are frequently present in smokeless tobacco products and may also be carcinogenic and have other detrimental health outcomes [5-8]. According to the National Cancer Institute and Centers for Disease Control and Prevention report, 2014 summarized the available evidence on the health effects of use of smokeless tobacco, drawing the following conclusions: The associations between smokeless tobacco use and adverse health effects differ by type of product. Smokeless tobacco products cause addiction, precancerous oral lesions, and cancer of the oral cavity, oesophagus, and pancreas, as well as adverse reproductive developmental effects including stillbirth, pre-term birth, and low birth weight. The evidence suggests that some, but not all, smokeless tobacco products are associated with increased risk of fatal ischemic heart disease, fatal stroke, and type 2 diabetes; more studies are needed to clarify any causal associations. There is insufficient evidence to assess whether smokeless tobacco products are associated with increased risks of lung cancer, cervical cancer, and hypertension. A 2016 systematic review and meta-analysis similarly concluded that there is an association between ever use of smokeless tobacco and risk of fatal ischemic heart disease and stroke. It is also important to note that-in comparison with the extensive research linking smoking with adverse health outcomes - evidence on the health effects of smokeless tobacco is far less comprehensive. Information on dose-response relationships, prevalence estimates, and confounding variables are often sparse, while the novelty of some products may not allow for a full understanding of long-term risks. Comprehensive monitoring of use of smokeless tobacco and its shortand long-term effects on health outcomes are required, particularly in regions with high prevalence [8-9]. Despite the high prevalence of smokeless tobacco (SLT) use among adults in Bangladesh, smokeless tobacco (SLT) was not included in the Tobacco Control Law till 2013. Information on SLT use among Bangladeshi people is inadequate for policymaking and implementing effective control measures. Evidence suggests that in Bangladesh, SLTs range from unprocessed to processed or manufactured products including SadaPata, Zarda, Gul, and Khoinee. Over 27\% of Bangladeshi adults aged 15 years and older use SLT in one form or another. SLT use is associated with age, sex, education, and socioeconomic status. SLT consumption has reportedly been associated with increased prevalence of 
heart diseases, stroke, and oral cancer and led to around 320,000 disability adjusted life years lost in Bangladesh in 2010. No cessation service is available for SLT users in public facilities. Compared to cigarettes, taxation on SLT remains low in Bangladesh. The amendment made in Tobacco Control Law in 2013 requires graphic health warnings to cover $50 \%$ of SLT packaging, ban on advertisement of SLT products, and restriction to sale to minors. However, implementation of the law is weak. As the use of SLT is culturally accepted in Bangladesh, culturally appropriate public awareness program is required to curb SLT use along with increased tax and cessation services [10]. The main purpose of the study was to find out the impact of Smokeless Tobacco (SLT) use among the women's health in the selected old town of Bangladesh.

\section{Method}

This is a descriptive type of cross-sectional study on the impact of Smokeless Tobacco (SLT) use among the women's health in the selected old town of Bangladesh. The study was conducted in a selected old town named Wari. Wari is a place where most of the people especially women use Smokeless tobacco (SLT) and tobacco products in Dhaka city. For availability of good number of study population this area was selected purposively as the site of data collection because there was time constraint. Study population was women who are resident in Wari, old town of Bangladesh. The study was carried out from April 2012 to June 2012. Data collection was done on the first two weeks of May 2012, tabulation and data analysis was done during $3^{\text {rd }}$ and $4^{\text {th }}$ week of the month. Due to time constrain and limited facilities sample size was 105 who were women living in old town of Bangladesh. A purposive sampling technique was used to get a total of 105 respondents. Inclusion Criteria: The respondent will be women using any form of Smokeless Tobacco (SLT) from a household irrespective of age living in old Dhaka. Voluntary participation. Exclusion Criteria: Women living in old Dhaka using any form of smoked tobacco was excluded. A structured questionnaire was development based on the objective, contents, and variables of the study. Extensive literature review was done before the development of the primary data collection tools. It was finalized after modification and correction based on the finding of questionnaire pretesting and finalized in both Bengali and in English. Data were collected by using the questionnaire through face-to-face interviews with the respondents. Questionnaire like a socio-demographic variable, Information about smokeless tobacco use and Oral hygienic practice. Before filling the questionnaire, the purpose of the study was explained. Collected data was cleaned and edited by the investigator himself. The data were processed manually tabulated and analyzed based on the objectives of the study. Data analyzed by using statistical package for social science (SPSS)-version 17. The result was calculated with help of an electronic calculator. Data was presented in tubular, forms analyzed, and the table and graph followed interpretation of results.

\section{Results}

\begin{tabular}{|l|c|c|}
\hline \multicolumn{1}{c}{ Table 1. Distribution of the respondents by their occupation } \\
& & Percent \\
\hline \hline Occupation & Frequency & 1.9 \\
\hline \hline Service holder & 5 & 19 \\
\hline \hline Businesswomen & 20 & 62.9 \\
\hline \hline Housewives & 77 & 16.2 \\
\hline \hline Day labourer & 3 & 100 \\
\hline \hline Total & 105 & \\
\hline
\end{tabular}

Table 1 shows distribution of the respondents by their occupation whereas out of 105 respondents maximum $62.9 \%$ were the housewives and only $1.9 \%$ were service holder. On the other hand, businesswomen and day laborer 
represent very close to each other those were subsquently $19 \%$ and $16.2 \%$.

\begin{tabular}{|c|c|c|}
\hline & & $n=31,82,19,49$ \\
\hline Characteristics & Frequency & Percent \\
\hline Sadapata (>10 years) & 15 & 48.4 \\
\hline Zarda (< 5 years) & 30 & 36.6 \\
\hline Gul (5 years) & 10 & 52.6 \\
\hline Khaini (5 years) & 19 & 38.8 \\
\hline
\end{tabular}

Table 2 represent the distribution of the respondents by the duration of using Smokeless Tobacco (SLT) with betel leaf (Sadapata, Zarda, Gul, Khaini) where as 48.4\% using sadapata, 36.6\% using zarda, 52.6\% using gul and $38.8 \%$ using khaini from respectively both more than 10 years and within 5 years.

\begin{tabular}{|c|c|c|}
\hline \multicolumn{1}{|c|}{ Table 3. Distribution of the respondents by reasons behind using Smokeless Tobacco (SLT) } \\
$\mathbf{n = 1 0 5}$ \\
\hline \hline $\begin{array}{c}\text { Reasons behind using } \\
\text { Smokeless Tobacco (SLT) }\end{array}$ & Frequency & Percent \\
\hline \hline For addiction or habituation & 39 & 37.1 \\
\hline \hline For fun & 42 & 40 \\
\hline \hline For relief from tiredness & 2 & 1.9 \\
\hline \hline For relief from tension & 2 & 1.9 \\
\hline \hline For relief from toothache & 20 & 19 \\
\hline \hline Total & 105 & 100 \\
\hline
\end{tabular}

Table 3 revealed that the reasons behind using smokeless tobacco was stated as fun by $40 \%$ respondents, as addiction or habituation by $37.1 \%$ respondents, as relief from toothache by $19 \%$ and as relief from tiredness $\&$ relief from tension by $1.9 \%$.

Table 4. Distribution of the respondent's opinion cause of any harm in the oral cavity by Smokeless Tobacco (SLT) use

$\mathrm{n}=105$

\begin{tabular}{l|c|c}
\hline $\begin{array}{l}\text { Opinion cause of any harm in the oral } \\
\text { cavity by Smokeless Tobacco (SLT) use }\end{array}$ & Frequency & Percent \\
\hline \hline Yes & 33 & 31.4 \\
\hline \hline No & 72 & 68.6 \\
\hline \hline Total & 105 & 100 \\
\hline
\end{tabular}


Table 4 shows that out of 105 respondents, almost $68.6 \%$ think smokeless tobacco do not cause any harm in the oral cavity while only $31.4 \%$ stated smokeless tobacco cause harm in the oral cavity.

\begin{tabular}{|c|c|c|c|c|c|}
\hline \multicolumn{6}{|c|}{ Table 5. Relationship between occupation and regular use of Smokeless Tobacco (SLT) } \\
\hline & & & & & $\mathrm{n}=\mathbf{1 0 5}$ \\
\hline \multirow{3}{*}{ Occupation } & \multicolumn{4}{|c|}{ Regular use of smokeless tobacco } & \multirow{3}{*}{ Total } \\
\hline & \multicolumn{2}{|c|}{ Yes } & \multicolumn{2}{|c|}{ No } & \\
\hline & Frequency & Percent & Frequency & Percent & \\
\hline Housewives & 45 & 66.2 & 21 & 31.8 & 66 \\
\hline $\begin{array}{l}\text { Others (businesswomen, day } \\
\text { laborer, service holder) }\end{array}$ & 33 & 84.6 & 6 & 15.4 & 39 \\
\hline Total & 78 & 74.3 & 27 & 25.7 & 105 \\
\hline
\end{tabular}

$\chi 2=3.466 ; p<0.05$

Table 5 shows the distribution of the respondents by occupation and regular use of smokeless tobacco. Among the housewives $66.2 \%$ uses Smokeless Tobacco (SLT) regularly and whereas in $84.6 \%$ of others groups (businesswomen, day laborer, and service holder) uses smokeless tobacco regularly. Study results show there was a significant association between occupation and regular use of Smokeless tobacco (SLT).

\section{Discussion}

This cross-sectional descriptive study was carried out to find out the impact of Smokeless Tobacco (SLT) use among the women's health in the selected old town of Bangladesh. Total 105 respondents were interviewed and were selected purposively. As the old town in Bangladesh is a density populated and congested area and due to limited facilities, they do not give enough preference about their improvement on socio-economic status. By profession out of $105 \%$ respondent's shows that $63 \%$ were housewives, $19 \%$ were businesswomen, $16.2 \%$ were day laborer and only $1.9 \%$ was service holder.

The finding is near about similar to the study conducted by Jalil MA. A study on prevalence of tobacco consumption habits among the rural people in a selected Thana of Gazipur district. Dissertation, NIPSOM 1997, showed that tobacco consumption habits were highly prevalent in low monthly family income group and most common among the housewives $(40 \%)$ [11].

In this study found that out of 105 respondents, the reasons behind using smokeless tobacco were stated as fun by 40 $\%$ respondents, as addiction or habituation by $37.1 \%$ respondents, as relief from toothache by $19 \%$ and as relief from tiredness \& relief from tension by $1.9 \%$ Above finding is not similar to the study conducted by Jalil MA. Prevalence of tobacco consumption habits among the rural people in a selected Thana of Gazipur district, Dissertation, NIPSOM 1997 showed that about 49\% respondents were motivated by friends to start tobacco consumption habits, $28.7 \%$ due to family influence and $20.5 \%$ of the respondents started due to curiosity [11]. My opinion is peoples living in old Dhaka are culturally and traditionally habituated to use smokeless tobacco while in others areas in Bangladesh peoples living in Gazipur district are not so. Above finding is near about like the study conducted by M Ahmed et al. Out of 719 students, $22 \%$ were current smokers and the rest $78 \%$ were non-smokers. Half of the students reportedly mentioned that they started smoking due to peer pressure followed by curiosity $(34 \%)$ to avoid anxiety and tension (28\%), feeling of maturity (14\%), symbol of manliness (9\%), unhappy family environment $(8.2 \%)$, However $24.5 \%$ of the respondents mentioned that they started smoking without any reason [14]. In this study according to the type of smokeless tobacco use $45.3 \%$ used Zarda, $10.5 \%$ used gul, $17.1 \%$ used SadaPata, and $27.2 \%$ used Khaini. About $38.7 \%$ respondents were using SadaPata five times and above per day. 
About $48.4 \%$ respondents were using SadaPata for more than 10 years. The study conducted by Mahiuddin MA. A study on tobacco consumption habits among the workers of a bidi (bin) factory in Bangladesh revealed that out of 275 workers interviewed $74.55 \%$ were found to be as tobacco consumers. Among them $86.83 \%$ were smoked biri / Cigarette. $40 \%$ were chewed pan with tobacco and $12.20 \%$ used gul [12]. My opinion is in old Dhaka peoples uses smokeless tobacco as like as fun and entertainment to the others from the ancient period to till date mostly Zarda, Khaini, Gul, and SadaPata while the workers of a bidi (bin) factory in Bangladesh are not so. In this study about $68.6 \%$ respondents think smokeless tobacco do not cause harm in the oral cavity while only $31.4 \%$ stated smokeless tobacco cause harm in the oral cavity.

Among them one third (30.3\%) answered ulcer occurs in them out due to smokeless tobacco use, $27.3 \%$ thought that it causes stain in the teeth, $12.1 \%$ think that it causes loss of appetite and $27.3 \%$ think that it causes stain in the teeth \& loss of appetite. It was also found that nearly $79.9 \%$ of adult American men thought tobacco snuff increase the risk of cancer whereas $83.8 \%$ adult American men considered chewing tobacco increases cancer risk. Among those who chew tobacco leaves, $71.5 \%$ knew the risk associated with it as compared to those who did not chew tobacco $[13,14,15]$. The finding is near about same with this study. According to the relationship between occupation and regular use of smokeless tobacco, among the housewives $66.2 \%$ uses smokeless tobacco regularly and whereas in $84.6 \%$ of others group (businesswomen, day laborer and service holder) uses smokeless tobacco regularly. There was significant association between occupation and regular use of smokeless tobacco $(\mathrm{p}<0.05)$. Above finding is nearly similar to the study conducted by Jalil MA. Prevalence of tobacco consumption habits among the rural people in a selected Thana of Gazipur district, Dissertation, NIPSOM 1997 showed that the prevalence rate of tobacco consumption among the study population was $36.14 \%$. Tobacco consumption habits were highly prevalent in low monthly family income group and most common among the housewives (40\%) [11].

Though there were very limited study was conducted on Smokeless tobacco (SLT). For this reason, more and more research need to be performed in order to help the researcher to give more information as well as discussion needs to be addressed about this problem in the matter.

\section{Conclusion}

This Smokeless Tobacco (SLT) constitutes more than 50\% of tobacco use among men and women in Bangladesh yet less received attention in tobacco control policies and action because of perceived less harmful effects than smoking and sociocultural aspect in Bangladesh. According to Tamak Birodhi Nari Jote -TABINAJ report on AntiTobacco Alliance report, 2016-Bangladesh has one of the highest rates of smokeless tobacco use in the world with 28 million users. It is mostly used among adults (27.2\%). Rates among women (27.9\%) are slightly higher than among men (26.4\%).

Furthermore, Control of the use of Smokeless tobacco (SLT) products has not been focused enough as a priority at national and international level. On global scenario, there are about 300 million SLT users in 70 countries, among them $89 \%$ are in India. India and Bangladesh make up $80 \%$ of the smokeless tobacco users of the world. The Tobacco control movement is more concentrated on "smoke-Free" rather than 'tobacco free' which may include both smoke and smokeless products [16].

By observing this scenario Tabinaj ( $1^{\text {st }}$ Women Allaiance againt Tobacco) launched $6^{\text {th }}$ March, 2011 in Bangladesh was affiliated with UBINIG (Policy Research for Development Alternative), a research organization engaged in conducting intensive research on tobacco cultivation and its impact on food production since 2006 with support from International Development and Research Centre (IDRC), Canada.

Finally considering the harmful impact with its consequences smokeless tobacco (SLT) use which was unfortunately unknown and unaware by the general population mostly women. It was reflected in my research about 
$63 \%$ of users were housewives. So, it is necessary to implement a very strong comprehensive monitoring and evaluation system both national and international region to stop the use of smokeless tobacco by involving government, non-government policy makers immediately. Now it is the time to realize in a true sense by our local political personnel and government to make emergency step and making network system so that we can make slogan Banning of Smokeless Tobacco (SLT) at national and international level around the world.

\section{Recommendation}

Based on the findings of the present study, following recommendations were made for the prevention of smokeless tobacco consumption habits.

1. Anti-smokeless tobacco health education should be regarded as part of general health education programme.

2. To make laws prohibiting the sale of smokeless tobacco to children and adolescent.

3. Mass media should be involved to address the injurious use of smokeless tobacco on oral health which though known but obscure to general population.

4. Systematic community-oriented oral health promotion programmes are needed for better control of oral diseases and hazards smokeless tobacco to be taught in all educational institution, religious centers to increase health awareness.

5. A prevention oriented oral health care policy, indeed, more advantageous than the curative approach. Health education related to oral health in the educational institutions may provide effective settings for oral health education programmes.

6. Research should be continued into the factors which influences smokeless tobacco using behaviour to determine mere appropriate in health education.

\section{DECLARATIONS}

\section{Research Ethical Approval}

Ethical permission for carried out the study was taken from local ethical committee (ethical review committee of NIPSOM) in due time. Written informed consent was taken from positive respondent with maintaining their full autonomy. All relevant documents including questionnaires were preserved under control of investigator. No individual information was supplied.

\section{Funding}

This research did not receive any specific grant from funding agencies in the public, commercial, or not-for-profit sectors.

\section{Author's contribution}

Authors personally try to aware the respondent about the negative impact of Smokeless Tobacco (SLT) by representing different health educational methods and media after the interviewing procedure. In addition, he also provides PowerPoint presentations to the Sapporo Dental College \& Hospital department faculty and the students about this research thoroughly.

\section{Completing Interest}

The author has an interest in future to do more research work on (Smokeless Tobacco) SLT.

\section{Conflicts of Interest}

The authors declared no potential conflicts of interest with respect to the research, authorship, and/or publication of this article. 


\section{Acknowledgment}

At first, my heartful gratitude to Almighty Allah whose invisible guidance helped me to complete this dissertation. It is a matter of great pleasure to express my deep sense of gratitude to Professor Dr. Saroj Kumar Majumder Director, NIPSOM, Dhaka, and other faculty members of the dissertation protocol Committee for their kind approval of this dissertation. My Profound regards and admiration to my respected guide Dr. Jahanara Begum, Assistant Professor \& Head, Dept of Health Education, NIPSOM, Dhaka for his scholarly guidance, Valuable Suggestions, kind supervision, and affectionate help in the preparation and completion of my dissertation in time. I would like to acknowledge my respect and appreciation to the Principal of Sapporo Dental College Hospital and other Teachers and Dental Surgeons for their sincere support and co-operation. I am also grateful to Dr. Kazi Jahangir Hossain Ph.D. Assistant Professor and Dr. Shamsul Alam, Medical officer, Department of Health Education, National Institute of Preventive and Social Medicine (NIPSOM) Mohakhali, Dhaka for their additional suggestions and encouragement in my research work. I am indebted to them for helping me in carrying out some important tasks in this field. I would like to acknowledge my respect and appreciation to Dr. Nurul Amin, Professor \& Head, Department of Oral \& Maxillofacial Surgery, Sapporo Dental College who with his in-depth knowledge in this field helped me a lot. I would like to thank Dr. Muktadir, Dr. Bithee, MD Hasan, Mrs. Rahima, Dr. Md. Shahed Jahan, Dr. Farzana Karim, Dr. Saima Akter, and other friends of mine for their help and support. I should like to thank my parents, wife, son, brothers, sister, for their prayerful concern and patience during the completion of my research work and dissertation.

Lastly, I would like to thank all those respondents who helped me with their precious time with patience

\section{REFERENCES}

[1] Poore TK. Johnson GK, Reinhardt RA, Organ cc. The effects of smokeless tobacco on clinical parameters of inflammation and gingival crevicular fluid prostaglandinE2, interleukin-1 alpha and interleukin-1 beta, J Periodontal, 1995; 66"177-183.

[2] National Cancer Institute and Centres for Disease Control and Prevention, Smokeless tobacco and public health: a global perspective. NIH publication no. 14-7983. Bethesda, MD: U.S. Department of Health and Human Services, Centers for Disease Control and Prevention and National Institutes of Health, National Cancer Institute; 2014.

[3] Leon ME, Lugo A, Boffetta P, Gilmore A, Ross H, et al. Smokeless tobacco use in Sweden and other 17 European countries. European Journal of Public Health, 2016.

[4] Australian Institute of Health and Welfare, National Drug Strategy Household Survey detailed report: 2013 Supplementary tables. AIHW: Canberra; 2014.

[5] Hossain MS, Kypri K, Rahman B, and Milton AH. Smokeless tobacco consumption in the South Asian population of Sydney, Australia: prevalence, correlates, and availability. Drug Alcohol Rev, 2014; 33(1):86-92.

[6] Ivers R, Indigenous Australians, and tobacco: a literature review. Menzies School of Health Research and the Cooperative Research Centre for Aboriginal and Tropical Health Darwin, Australia; 2001.

[7] Fagerstrom K, Gilljam H, Metcalfe M, Tonstad S, and Messig M. Stopping smokeless tobacco with varenicline: randomised double-blind placebo-controlled trial. British Medical Journal, 2010; 341(c6549).

[8] Rostron BL, Chang CM, van Bemmel DM, Xia Y, and Blount BC. Nicotine and toxicant exposure among US Smokeless tobacco users: Results from 1999 to 2012 national health and nutrition examination survey data. Cancer Epidemiology, Biomarkers \& Prevention, 2015.

[9] National Cancer Institute and Centers for Disease Control and Prevention, Smokeless tobacco, and public health: a global perspective. NIH publication no. 14-7983. Bethesda, MD: U.S. Department of Health and Human Services, Centers for Disease Control and Prevention and National Institutes of Health, National Cancer Institute; 2014.

[10] RumanaHuque, M. Mostafa Zaman, Syed MahfuzulHuq, Dhirendra N. Sinha, smokeless tobacco and Public health in Bangladesh, review article, September 27, 2017, IP: 27.147.204.166

[11] Jalil MA. A study on prevalence of tobacco consumption habits among the rural people in a selected Thana of Gazipur district. Dissertation, NIPSOM 1997.

[12] Mahiuddin M, A study on tobacco consumption habits among the workers of a Bidi (bin) factory in Bangladesh, 
Dissertation, NIPSOM, 1998.

[13] World health organization, WHO report on the global tobacco epidemic, Geneva: World Health Organization, 2008

[14] The health consequences of using smokeless tobacco, a report of the surgeon. General, Washington DC, US Department of health and human services, public health services 1986.

[15] Bangladesh GATS 2009, India GATS 2009, Indonesia National Socio Economics Survey 2004, Maldives STEPS Survey 2004, Myanmar STEPS Survey 2009, Nepal Non- communicable disease Risk factor survey 2008, Srilanka STEPS survey 2006, Thailand GATS 2009.

[16] Rumana Huque, M. Mostafa Zaman, Syed Mahfuzul Huq, Dhirendra N. Sinha, smokeless tobacco and Public health in Bangladesh, review article, September 27, 2017, IP: 27.147.204.166 